\title{
Complex process activation energy evaluated by combined utilization of differential and integral isoconversional methods
}

Roman Svoboda $^{1 *}$, Giorgio Luciano ${ }^{2}$

${ }^{1}$ Department of Physical Chemistry, Faculty of Chemical Technology, University of Pardubice, Studentska 573, 53210 Pardubice, Czech Republic.

${ }^{2}$ Istituto per lo Studio delle Macromolecole (ISMAC) - Sede di Genova, CNR, Via De Marini 6, 16149, Genova, Italy

\begin{abstract}
Performance of the differential and integral isoconversional methods of kinetic analysis was evaluated for complex processes with overlapping independent or consequent reaction mechanisms. Novel way of combined interpretation of the activation energy dependences provided by both differential and integral methods was developed, enabling precise determination of the true activation energies of the overlapping sub-processes. Fundamental part of this evaluation method is based on the existence of point of inflexion following the overshoot effect on the differential isoconversional dependence of activation energy on the degree of conversion. This point of inflexion was found to very well coincide with the higher activation energy. The lower true activation energy can be always determined from the integral isoconversional dependence. Universal pattern for interpretation of the isoconversional kinetic methods behavior was confirmed for all sub-processes with asymmetry in the range of $<-0.35 ; 0.35>$, covering majority of real-life data.
\end{abstract}

Keywords: kinetic analysis; solid-state; complex process; activation energy; isoconversional methods

\footnotetext{
"Corresponding author: Tel.: +420 466037346 E-mail address: roman.svoboda@upce.cz
} 


\section{Introduction}

Major portion of experimentally observed solid-state processes can be denoted as kinetically complex, i.e. in these reactions/transformations multiple kinetic mechanisms proceed simultaneously or their occurrence at least partially overlaps. Nature of the complexity can vary greatly. The occurring kinetic mechanisms can be associated with entirely different chemical reactions (e.g. overlapping melting and decomposition) [1-5], same type of transformation but with different products (e.g. formation of multiple crystalline phases from a glass) [6-10], or even similar product being formed but under different spatially-conditioned circumstances (e.g. similar reaction proceeding at the surface and in the volume of the material) [11-15]. Such large variety of kinetic complexity can often result in the overlap of processes with significantly different activation energies. In such case it is usually the isoconversional methods that are used for evaluation of the respective apparent activation energies $\mathrm{E}$ in dependence on the degree of conversion $\alpha$. Fundamental basis of these methods lies in a simultaneous evaluation of a series of measurements performed at different heating rates, where for each selected $\alpha$ value a corresponding E value is calculated.

All these methods originate from the base kinetic equation for the transformation rate $\mathrm{d} \alpha / \mathrm{dt}[16,17]:$

$$
d \alpha / d t=I \cdot A \cdot e^{-E / R T} \cdot f(\alpha)
$$

where $\alpha$ is the degree of conversion, $t$ is time, $T$ is temperature, $f(\alpha)$ is a substitute for a kinetic model, $I$ is the integrated area under the kinetic peak, $A$ is the pre-exponential factor and $E$ is the apparent activation energy of the process. Typologically, there are several types of isoconversional methods. Differential isoconversional methods utilize the base kinetic equation in its differential form (Eq. 1) and as such do not introduce any approximations to the evaluation - the most well-known representative of the differential isoconversional methods is the Friedman method (Eq. 2) [18]: 


$$
\ln \left(\frac{d \alpha}{d t}\right)_{\alpha}=-\frac{E}{R T_{\alpha}}+\text { const } .
$$

where $(\mathrm{d} \alpha / \mathrm{d} t)_{\alpha}$ and $T_{\alpha}$ are the conversion rate and temperature corresponding to arbitrarily chosen values of conversion $\alpha$. This method can be used for any temperature program isothermal, non-isothermal heating or cooling, complex step-wise programs, etc.; the only requirement is based on accurate determination of the quantities corresponding to the arbitrarily chosen values of $\alpha$. In practice this can lead to lower accuracy due to the $(\mathrm{d} \alpha / \mathrm{d} t)_{\alpha}$ term, which can be affected by e.g. subtraction of the thermokinetic background, quantity I (e.g. characteristic enthalpy associated with the process in case of the calorimetric measurements) being temperature dependent, or differentiation procedure in case of the default integral data.

Integral isoconversional methods, on the other hand, originate from the integral form of Eq. 1 and utilize various approximations to solve the arising temperature integral $g(\alpha)$. The first, rigid integral isoconversional methodologies were developed for the standard linear heating programs (the approximations of $g(\alpha)$ involved integration over temperature) and are based on simple linearization procedures; most often used methods that fall in this category are: OFW (Eq. 3) [19], KAS (Eq. 4) [20] or Starink (Eq. 5) [21]. More recently developed integral isoconversional methods provide increased accuracy by utilizing non-linear optimization, and (by employing integration over time) can be applied to data obtained under various temperature programs; one of the more commonly used methods from this rank is the one represented by Eqs. 6 and 7 [22]. However, these methods do not take a priori into account the potential (and quite common) variation of $\mathrm{E}$ with $\alpha$. This issue is addressed by the pseudo-differential (still integral in nature) method represented by Eq. 8 [23], where the integration assuming constant $\mathrm{E}$ is performed only over small time intervals.

$$
\begin{gathered}
\ln \left(q^{+}\right)=-1.0516\left(\frac{E}{R T_{\alpha}}\right)+\text { const } . \\
\ln \left(\frac{q^{+}}{T_{\alpha}^{2}}\right)=-\frac{E}{R T_{\alpha}}+\text { const. }
\end{gathered}
$$




$$
\begin{gathered}
\ln \left(\frac{q^{+}}{T_{\alpha}^{1.92}}\right)=-1.008 \frac{E}{R T_{\alpha}}+\text { const. } \\
\Phi(E)=\sum_{i=1}^{n} \sum_{j \neq i}^{n} \frac{J\left(E, T_{\alpha, i}\right) q_{j}^{+}}{J\left(E, T_{\alpha, j}\right) q_{i}^{+}} \\
J\left(E, T_{\alpha}\right)=\int_{0}^{T_{\alpha}} \exp \left(\frac{-E}{R T}\right) d T \\
J\left(E, T_{\alpha}\right)=\int_{T_{\alpha}-\Delta \alpha}^{T_{\alpha}} \exp \left(\frac{-E}{R T}\right) d T
\end{gathered}
$$

Despite the decades of usage of these equations for evaluation of complex kinetic data, the interpretation of the obtained E- $\alpha$ dependences is still not perfected. Note that the raw E- $\alpha$ dependences can be used for the predictions of the overall course of the complex process, but the values of individual activation energies attributed to the particular sub-processes can be difficult to extract from the overall dependence. In addition, the differential and integral isoconversional methods were always only compared regarding their accuracy and precision, and never considered to be complementary. In the present paper the theoretical simulations will be used to investigate the behavior of the differential and integral isoconversional methods under different complex process scenarios. New approach to the activation energy determination for the individual sub-processes will be introduced, based on the simultaneous utilization of the differential and integral isoconversional methods.

\section{Theoretical simulations}

All the calculations were performed using custom functions written in R-language. They are available in a package named takos (Thermo-Analytical Kinetic analysis) available to the Comprehensive R Archive Network (CRAN cran.r.project.org) and they are released under GNU General Public License, version 2. The package was designed in order to create a common workflow environment for kinetic data analysis that include the most common 
methodologies for determining the activation energy from non-isothermal analysis without the need of using multiple proprietary software and that can offer all the advantages of a scripting language. Note that for all calculations the data were interpolated so that the kinetic triplets $[\mathrm{T}, \mathrm{d} \alpha / \mathrm{dt}, \alpha]$ correspond exactly to the pre-selected values of the conversion degree $\alpha$.

\subsection{JMA processes datasets}

The base theoretically simulated datasets used to imitate various complex kinetics scenarios were based on the Johnson-Mehl-Avrami (JMA) [24-27] kinetics:

$$
f(\alpha)=m(1-\alpha)[-\ln (1-\alpha)]^{1-(1 / m)}
$$

where $m$ is the model kinetic exponent corresponding to the dimensionality of the process. The present work addresses independent and consequent/following processes (which have formally similar kinetic equations). For these processes the non-isothermal differential kinetic equation (derived from Eq. 1) can be written as:

$$
d \alpha / d T=\frac{1}{q^{+}} \cdot I_{1} \cdot A_{1} \cdot e^{-E_{1} / R T} \cdot f\left(\alpha_{1}\right)+\frac{1}{q^{+}} \cdot I_{2} \cdot A_{2} \cdot e^{-E_{2} / R T} \cdot f\left(\alpha_{2}\right)
$$

where $\mathrm{q}^{+}$is the applied heating rate. All JMA complex kinetics data were simulated for the following set of kinetic parameters: $\mathrm{E}_{1}=50 \mathrm{~kJ} \cdot \mathrm{mol}^{-1}, \mathrm{E}_{2}=300 \mathrm{~kJ} \cdot \mathrm{mol}^{-1}, \mathrm{~m}_{1}=2, \mathrm{~m}_{2}=2$, $\mathrm{I}_{1}=\mathrm{I}_{2}=0.50, A_{1}=10^{2.5} \mathrm{~s}^{-1}, A_{l}=10^{27} \mathrm{~s}^{-1}$, and heating rates $0.5,1,2,3,4,5,6,8,11,13,16$, $25,50,75,100,150,200,300$ and $400{ }^{\circ} \mathrm{C} / \mathrm{min}$. In order to cover different magnitude ratios of the sub-processes, two datasets were prepared under these conditions - one with $\mathrm{I}_{1}=0.30$ and $\mathrm{I}_{2}=0.70$, and the second with $\mathrm{I}_{1}=0.70$ and $\mathrm{I}_{2}=0.30$, respectively.

\subsection{AC processes datasets}

As the JMA kinetics covers only a very narrow, characteristic range of peak asymmetries, the empirical autocatalytic Šesták-Berggren (AC) model [1] was employed to prepare datasets with different peak asymmetries. The AC model function is expressed as: 


$$
f(\alpha)=\alpha^{M}(1-\alpha)^{N}
$$

where $\mathrm{M}$ and $\mathrm{N}$ are the kinetic exponents. Five different datasets were simulated (based on Eqs. 10 and 11) to cover majority of experimentally observed peak asymmetries, as well as situations with different $\mathrm{E}_{1} / \mathrm{E}_{2}$ ratios. Values of the kinetic parameters are for the five $\mathrm{AC}$ datasets listed in Table 1; within each dataset again the data-curves for heating rates $0.5,1,2$, $3,4,5,6,8,11,13,16,25,50,75,100,150,200,300$ and $400{ }^{\circ} \mathrm{C} / \mathrm{min}$ were simulated.

Note that the asymmetry is in the present article quantified via the Fraser-Suzuki equation [28-30]:

$$
y=a_{0} \exp \left[-\ln 2\left[\frac{\ln \left(1+2 a_{3} \frac{x-a_{1}}{a_{2}}\right)}{a_{3}}\right]^{2}\right]
$$

where $a_{0}, a_{1}, a_{2}$ and $a_{3}$ are the parameters corresponding to the amplitude, position, half-width and asymmetry of the peak (defined by $\mathrm{x}$ and $\mathrm{y}$ coordinates), respectively.

\section{Results}

The initial (and most thorough) exploration of the performance of the isoconversional methods in the complex process scenarios was done for the JMA kinetic datasets (see section 2.1. for data simulation details). Since the most basic and fundamental effect of various different activation energies being attributed to the overlapping sub-processes was already reported (although not systematically) several times in literature, the present article focuses on the so far not explored question of different selections of heating rates (out of the whole simulated dataset) to be engaged in the calculations. For this reason, 8 subsets of different heating rates were chosen to cover different types of overlaps and to demonstrate the possibilities of $\mathrm{q}^{+}$range choices during the isoconversional analysis - the heating rates included in each subset are listed in Table 2. In this way achieved types of complexity include very small overlaps, where only the borderline heating rates were included in the evaluations, 
as well as full overlaps, where $\mathrm{q}^{+}$from the middle of the considered range were used for the isoconversional analyses.

Starting with the very weak overlaps, Fig. 1 shows the data for the two borderline JMA overlaps that occur when either the $0.5-3{ }^{\circ} \mathrm{C} \cdot \mathrm{min}^{-1}$ or the $150-400{ }^{\circ} \mathrm{C} \cdot \mathrm{min}^{-1}$ heating rate ranges are evaluated. As can be seen from the graphs with depicted complex data-curves (30/70 and $70 / 30$ terms denote the $I_{1} / I_{2}$ ratio), the overlaps are indeed very small, where only two out of the four evaluated data-curves show few percent overlay (index "1" always corresponds to the smaller and wider peaks, and index " 2 " always corresponds to the tall sharp peaks). The corresponding right column graphs then show the resulting E- $\alpha$ dependences provided by the differential and integral isoconversional methods. Note that in all cases presented in this paper all the respective tested integral methods (Eqs. $3-7$ ) and differential methods (i.e. methods providing differential type of output; Eqs. 2 and 8) gave extremely similar results (differences within $0.5 \%$ for all integral methods; differences within $2 \%$ for the two differential methods). Thus, for practical purposes it does not matter whether one uses the very slightly more precise equations (see e.g. [31] for their classification), the shape of the E- $\alpha$ dependences and general conclusions derived from based on them will be the same. Therefore, only one representative from each group of equations (integral vs. differential) will be shown to improve clarity of the figures. Due to the very small overlaps the $E-\alpha$ dependences in Fig. 1 perfectly indicate both $E_{1}$ and $E_{2}$ as well as their correspondence to the particular set of sub-processes. In addition, also the $I_{1} / I$ ratio is very well indicated by the sharp increases/drops of the E- $\alpha$ dependences at $\alpha$ either 0.30 or 0.70 , depending on the respective positions of the kinetic sub-peaks. To stress the relevancy of this information, the vertical dashed lines in the E- $\alpha$ graphs will always show the $I_{1} / I$ value (denoted also in the left-hand graphs) - in this way it is shown how the heating rate changes 
the mutual position of the kinetic sub-processes with significantly different activation energies and, consequently, how the E- $\alpha$ dependences are changed.

Results for the larger low- $\alpha$ (with respect to the sub-process No. 2, the one with higher E) overlaps are shown in Fig. 2; note the intentional selection of narrower $\left(3-6{ }^{\circ} \mathrm{C} \cdot \mathrm{min}^{-1}\right)$ and wider $\left(3-11^{\circ} \mathrm{C} \cdot \mathrm{min}^{-1}\right)$ range of $\mathrm{q}^{+}$demonstrating the negative effect of increased overlap that can be prevented by sole choice of data-curves included in the evaluation. The E- $\alpha$ dependences depicted in Fig. 2 show the most important difference between the integral and differential isoconversional methods - the existence of overshoots and undershoots in case of the differential methods, where the integral methods always provide only E values in-between the two activation energy limits $\left(\mathrm{E}_{1}\right.$ and $\left.\mathrm{E}_{2}\right)$. This behavior of the differential methods is also crucial for the main point of the present article - determination of the true $E_{1}$ and $E_{2}$ values from the isoconversional E- $\alpha$ dependences. Whereas the low E limit is in Fig. 2 always clearly identifiable based on the $\mathrm{E}$ data from the integral methods, it is not the case for the upper $\mathrm{E}$ limit $\left(E_{2}\right)$. It can be, however, seen that the differential $E-\alpha$ dependence after its overshoot always intersects (as a rule of thumb) with the indicated true $\mathrm{E}_{2}$ value at the point where the convex part of the E- $\alpha$ dependence changes to the concave course (i.e. at the first point of inflexion after the overshoot). The second rule-of-thumb for interpretation of the E- $\alpha$ dependences is (as mentioned above) that the $\mathrm{E}$ values provided by the integral methods always lie in-between the true $E_{1}$ and $E_{2}$ values; in other words, the true value of higher $E$ is always above the integral E- $\alpha$ dependence (which can help identify the correct point of inflexion - see the graph for $\mathrm{I}_{1} / \mathrm{I}_{2}=70 / 30$ and $\mathrm{q}^{+}$range $3-11^{\circ} \mathrm{C} \cdot \mathrm{min}^{-1}$ ). These two simple rules will now be tested and discussed throughout the paper for all other different cases of complex kinetics behavior.

Graphs in Fig. 3 show the high- $\alpha$ overlaps (with respect to the sub-process No. 2, the one with higher E) and the corresponding differential and integral E- $\alpha$ dependences. The data 
simulated for $I_{1} / I_{2}=30 / 70$ behave again in correspondence with the above suggested concept; the lower E limit is again indicated by the integral data whereas the upper E limit corresponds to the point of inflexion on the differential E- $\alpha$ dependence (note that for the high- $\alpha$ overlaps the $\mathrm{I}_{1} / \mathrm{I}_{2}$ ratio can be derived from the point where the differential data intersect with the low $\mathrm{E}$ limit). More difficult situation arises in case when the process with lower $\mathrm{E}$ is dominant with respect to $I$ (the $70 / 30$ cases for the present data). In case of larger overlaps with $I_{1} / I_{2}=70 / 30$ no point of inflexion occurs on the differential E- $\alpha$ dependence before it intersects with the integral E- $\alpha$ data. In such case the upper E limit is always above the differential E- $\alpha$ dependence. Very rough estimate of the upper E limit could be made based on the magnitude of the high-E plateau on the integral E- $\alpha$ dependence: the larger/wider the plateau, the closer the upper E limit is to the top of the differential E- $\alpha$ dependence. However, the easiest (and most precise) way how to determine the upper E limit would in this case be the further reduction of evaluated $\mathrm{q}^{+}$(by omitting the data-curves simulated for $\mathrm{q}^{+}$lower than $50{ }^{\circ} \mathrm{C} \cdot \mathrm{min}^{-}$ ${ }^{1}$ ) resulting in smaller degree of overlap and the consequent change of the two isoconversional dependences towards their "standard" appearance.

The interpretation issue associated with the full overlaps where the lower-E process is the dominant one is further demonstrated in Fig. 4. The two cases with $I_{1} / I_{2}=30 / 70$ again behave and can be evaluated in the standard way. The situation with $I_{1} / I_{2}=70 / 30$ and all $\mathrm{q}^{+}$being included is apparently massively distorted (with respect to estimation of the upper $\mathrm{E}$ limit) but could very easily solved simply by evaluating only selected data-curves. The most difficult issue arises for the case with $\mathrm{I}_{1} / \mathrm{I}_{2}=70 / 30$ and $\mathrm{q}^{+}$range $8-16{ }^{\circ} \mathrm{C} \cdot \mathrm{min}^{-1}$. In this case, when only fully overlapping curves of the processes with significantly different E values and the lower-E process being dominant can be measured, there is no mathematic way or a processing trick that could be used to reliably and precisely determine the upper E limit via 
utilization of isoconversional methods. Instead, one of the alternative methods needs to be used - these will be listed in section 4.1.

\section{Discussion}

In the previous section the behavior of isoconversional methods was introduced for the cases of independent and consequent/following complex kinetic processes based on the JMA kinetics. In order to generalize the findings, the flexible AC model was used to simulate processes with different asymmetries (the JMA kinetics exhibits only very narrow range of kinetic peak asymmetries) and to confirm the universality of the rules for interpretation of the isoconversional $\mathrm{E}-\alpha$ dependences (with respect to determination of the true $\mathrm{E}$ values of the involved sub-processes). The analysis of the AC data starts with the dataset with $\mathrm{M}=1$ and $\mathrm{N}=2$, which exhibits an opposite asymmetry in comparison with the JMA model (the same magnitude but positive sloping) - see Figs. 5 and 6 (the corresponding overlaps of the kinetic data-curves are included in the Supplemental online material; the kinetic parameters were chosen so that approximately similar degrees of overlaps were achieved for the respective $\mathrm{q}^{+}$ ranges). As can be seen, very similar conclusions can be derived also for the complex processes with opposite asymmetry to that introduced in the Results section. The integral E- $\alpha$ dependences are again always within the E limits and the lower E limit can be determined from the lowest achieved integral E- $\alpha$ value. The differential E- $\alpha$ dependences again exhibit the characteristic over- and undershoots, where the upper E limit can be determined from the E value at the point of inflexion following the overshoot effect. In certain cases (full overlaps, most often when the sub-process with lower E is dominant - see e.g. the graph with $8-$ $16{ }^{\circ} \mathrm{C} \cdot \mathrm{min}^{-1}$ in Fig. 5) the descending part of the differential $\mathrm{E}-\alpha$ dependence is monotonic and does not exhibit point of inflexion (or this point is below the integral E- $\alpha$ dependence). In such case the width of the high-E plateau shown by the integral E- $\alpha$ data indicates how far 
above this plateau the upper E limit lies (the wider the plateau, the closer the upper E limit). Generally, again except for the full overlaps without the possibility to measure kinetic data at higher or lower $\mathrm{q}^{+}$the universal advice would be to limit the average degree of overlap by excluding the data-curves with largest overlays.

In addition to the high positive AC asymmetry ( 0.35 according to the Fraser-Suzuki classification [28-30] for the combination of $\mathrm{M}=1$ and $\mathrm{N}=2$ ), similar testing was done also for the AC processes with intermediate kinetic asymmetries and for the AC process with high negative asymmetry (similar to that of JMA kinetics) - see Table 1 for the values of AC kinetic exponents and corresponding Fraser-Suzuki asymmetries. Resulting E- $\alpha$ dependences for selected $\mathrm{q}^{+}$ranges $\left(3-6,3-11,13-100\right.$ and $\left.25-100{ }^{\circ} \mathrm{C} \cdot \mathrm{min}^{-1}\right)$ are depicted in Figs. 7 and 8; the raw data-curves are included in the Supplemental online material. The base findings reported above for the JMA kinetics (inherent high negative asymmetry) and AC kinetics with high positive asymmetry are apparently valid also for the intermediate asymmetries and thus can be confirmed for the whole $<-0.35 ; 0.35>$ interval of peak asymmetries (scaling according [28-30]). In addition, based on monitoring the development of the differential E- $\alpha$ dependence course, it can be seen that for sub-processes with negative asymmetries the differential E- $\alpha$ data are easy to interpret in case of low- $\alpha$ overlaps, whereas for sub-processes with positive asymmetries it is the high- $\alpha$ overlaps that result in easily interpretable differential E- $\alpha$ dependences (exhibiting the point of inflexion after the overshoot). In the opposite cases (high- $\alpha$ overlaps for negative asymmetries and low- $\alpha$ overlaps for positive asymmetries) the interpretation of the combined differential and integral isoconversional dependences can be tricky due to the lack of the point of inflexion on the differential E- $\alpha$ data. Also note, that the four AC datasets presented in Figs. 7 and 8 were simulated for $I_{1} / I_{2}=50 / 50$ - the increased dominance of the low-E sub-process would lead to increased difficulty in the estimation of the true high-E limit (denoted $\mathrm{E}_{2}$ in the present paper). 


\subsection{Alternative evaluation and data-processing methods}

It has been shown that in case of the strongly overlapping independent or consequent kinetic processes, where the sub-process with lower $\mathrm{E}$ is dominant, it can be difficult to determine the activation energy of the sub-process with higher $\mathrm{E}$ based on the interpretation of the isoconversional E- $\alpha$ dependences. Occurrence of this issue depends on the asymmetry of the overlapping kinetic peaks - difficulties arise for high- $\alpha$ overlaps at negative asymmetries and for low- $\alpha$ overlaps at positive asymmetries. In these cases, the alternative evaluation or data-processing methods need to be used to precisely determine the activation energy for the sub-process with higher E.

Starting with the data evaluation, it has been shown in [32] that the $T_{\mathrm{p}}$-based methods (where $T_{p}$ stands for the temperature at which the reaction proceeds at maximum rate [31]), such as the original Kissinger method [33] (see Eq. 13), can very accurately estimate the true activation energies of the complex overlapping sub-processes.

$$
\ln \left(\frac{q^{+}}{T_{p}^{2}}\right)=-\frac{E}{R T_{p}}+\text { const. }
$$

Since the issue with isoconversional methods occurs at high-degree or full overlaps, the $\mathrm{T}_{\mathrm{p}^{-}}$ based methods can in those cases utilize extrapolation of the shoulders manifesting alternately on both sides of the "main" kinetic peak due to the increased $\mathrm{q}^{+}$to determine the lower E limit. For determination of the higher $\mathrm{E}$ limit the $\mathrm{T}_{\mathrm{p}}$-based methods can simply utilize the fact that the small changes of the thermo-kinetic background [34 - 36] (overlap with low-E subprocess counts too) do not influence the output of these methods and hence the method can be used in a straight-forward way on the sharper (high-E) kinetic peaks. Another, computationally a lot more challenging way how to determine the true activation energies of the involved sub-processes, is the deconvolution of the complex kinetics. The separation of the kinetic sub-peaks can be done either by mathematic deconvolution (see e.g. [37 - 39]) or 
by kinetic deconvolution (see e.g. [40-42]) - more on the topic of advantages and disadvantages of these methods can be found in [43, 44].

With regard to the data-processing tricks and tips, it has been already mentioned above that arbitrary omitting of data-curves obtained at certain heating rates that in consequence leads to reduction of the average degree of sub-processes overlap can largely improve the interpretation possibilities for the isoconversional methods. This holds even if the reduced number of evaluated data-curves decreases to 3 . When performing the thermo-analytical measurements intended for complex process kinetic calculations, it is therefore recommended to make an initial screening at highest and lowest possible $\mathrm{q}^{+}$, perform measurements at a variety of heating rates [45] but particularly focus on those exhibiting low degrees of overlaps (even if the change of heating rate should be very small).

Moreover, a multi-step experimental procedure can be applied when a dominant process with low activation energy overlaps with another process that exhibits higher E. First, isothermal annealing applied below the onset of the complex process will either eliminate or at least reduce the magnitude of the initially dominant process with lower E (due to the lower activation energy the process will proceed at significantly higher rate when extrapolated to lower temperature). Then the material can be cooled and heated at a standard way at constant $\mathrm{q}^{+}$. Due to the potentially increased reproducibility issues influencing the isoconversional evaluation, it would be recommended to perform the first step for a whole batch of material so that the consequent linear heating scans could be produced for a material with uniform properties (samples taken out from the annealing-processed batch). It is also essential to check that the asymmetry or activation energy of the high-E sub-process does not change with duration of the annealing step, because this would indicate other than independent or consequent relationship between the involved reactions. 


\section{Conclusions}

Combined utilization of differential and integral isoconversional methods was studied in the environment of theoretically simulated independent and following complex kinetic processes with the following conclusions:

- all integral methods provide for practical reasons similar E- $\alpha$ dependences, where the differences in $\mathrm{E}$ values are below $~ 3 \%$, i.e. well below the experimentally achieved errors arising from the data reproducibility. The same conclusion is valid also for the differential isoconversional methods (including the pseudo-differential ones).

- integral isoconversional methods always provide $\mathrm{E}$ values in-between the true values of activation energies corresponding to the involved sub-processes (low-E and high-E limits). The integral E- $\alpha$ dependences also always (for any asymmetry and any degree of overlap) well indicate the value of the low-E limit, i.e. the activation energy for the sub-process with lower E.

- in most cases the differential E- $\alpha$ dependences exhibit characteristic over- and undershoots. The high-E limit (the activation energy for the sub-process with higher E) can be determined from the $\mathrm{E}$ value at the point of inflexion following the overshoot effect on the differential E- $\alpha$ dependence.

- in case of fully overlapping sub-processes where the sub-process with lower E is dominant, the descending part of the differential E- $\alpha$ dependence is monotonic and does not exhibit point of inflexion (or this point is below the integral E- $\alpha$ dependence). This behavior is more pronounced in case of high- $\alpha$ overlaps for negative asymmetries and low- $\alpha$ overlaps for positive asymmetries. In such cases the height and width of the plateau shown by the integral E- $\alpha$ data can provide a rough estimation for the high-E limit. It is however strongly recommended to confirm this value by using an alternative method - see section 4.1. 
All above-mentioned conclusions are valid for the overlapping kinetic processes with the asymmetries in the range $<-0.35 ; 0.35>$ (scaled in terms of Fraser-Suzuki function). Extensive testing of these findings for real-life experimental complex kinetic data is in progress.

\section{Acknowledgments}

This work has been supported by the Czech Science Foundation under project No. 1711753S. We gratefully acknowledge the support of NVIDIA Corporation with the donation of the Titan Xp GPU used for this research for performing calculations.

\section{References}

[1] H. Ebrahimzade, G.R. Khayati, M. Schaffie. Thermal decomposition kinetics of basic carbonate cobalt nanosheets obtained from spent Li-ion batteries: Deconvolution of overlapping complex reactions. Trans. Nonferrous Met. Soc. China 28 (2018) 12651274.

[2] M. Nakano, T. Wada, N. Koga. Exothermic Behavior of Thermal Decomposition of Sodium Percarbonate: Kinetic Deconvolution of Successive Endothermic and Exothermic Processes. J. Phys. Chem. A 119 (2015) 9761-9769.

[3] Y. Yamamoto, N. Koga. Thermal Decomposition of Maya Blue: Extraction of Indigo Thermal Decomposition Steps from a Multistep Heterogeneous Reaction Using a Kinetic Deconvolution Analysis. Molecules 24 (2019) 2515.

[4] J. Liu, L. Luo, Y. Hu, F. Wang, X. Zheng, K. Tang. Kinetics and mechanism of thermal degradation of vegetable-tanned leather fiber. J. Leather Sci. Eng. 1 (2019) 9

[5] P. Brachi, F. Miccio, M. Miccio, G. Ruppolo. Pseudo-component thermal decomposition kinetics of tomato peels via isoconversional methods. Fuel Process. Technol. 154 (2016) 243-250.

[6] R.R. Pela, L.S. Cividanes, D.D. Brunelli, S.M. Zanetti, G.P. Thim. Kinetic study of $\alpha-$ BZN crystallization obtained from chemical method. Mat. Res. 11 (2008) 289-293.

[7] A.A. Joraid, M. Abu El-Oyoun, N. Afify. Phase separation and crystallization kinetics studies of amorphous $\mathrm{Si}_{10} \mathrm{Te}_{90}$. Chalcogenide Letters 13 (2016) 79-89.

[8] M.M. Vasic, D.M. Minic, V.A: Blagojevic, T. Zak, N. Pizutova, B. David, D.M. Minic. Thermal stability and mechanism of thermally induced crystallization of $\mathrm{Fe}_{73.5} \mathrm{Cu}_{1} \mathrm{Nb}_{3} \mathrm{Si}_{15.5} \mathrm{~B}_{7}$ amorphous alloy. Acta Phys Pol. A 128 (2015) 657-660.

[9] Y.B. Saddeek, E.R. Shabaan, K.A. Aly, I.M. Sayed. Crystallization kinetics of $\mathrm{Li}_{2} \mathrm{O}-$ $\mathrm{PbO}-\mathrm{V}_{2} \mathrm{O}_{5}$ glasses. Physica B 404 (2009) 2415-2418.

[10] C.M.O. Muller, A.T.N. Pires, F. Yamashita. Characterization of Thermoplastic Starch/Poly(Lactic Acid) Blends Obtained by Extrusion and Thermopressing. J. Brazil. Chem. Soc. 23 (2012) 426-434.

[11] B. Munjal, A.K. Bansal. Impact of tert-butyl alcohol on crystallization kinetics of gemcitabine hydrochloride in frozen aqueous solutions. J. Pharm. Sci. 104 (2015) 8797. 
[12] I. Keridou, L.J. del Valle, L. Funk, P. Turon, I. Yousef, L. Franco, J. Puiggali. Isothermal Crystallization Kinetics of Poly(4-hydroxybutyrate) Biopolymer. Materials 12 (2019) 2488.

[13] M. Vasic, V.A. Blagojevic, N.N. Begovic, T. Zak, V.B. Pavlovic, D.M. Minic. Thermally induced crystallization of amorphous $\mathrm{Fe}_{40} \mathrm{Ni}_{40} \mathrm{P}_{14} \mathrm{~B}_{6}$ alloy. Thermochim. Acta 614 (2015) 129-136.

[14] V. Pistor, D. De Conto, F.G. Ornaghi, A.J. Zattera. Microstructure and crystallization kinetics of polyurethane thermoplastics containing trisilanol isobutyl POSS. J. Nanomater. 1 (2012) 283031.

[15] M. Kakiage, M. Sekiya, D. Tomiya, T. Yamanobe, H. Uehara. Isothermal Crystallization Behavior of Polyethylene/Polystyrene Block Copolymer Estimated by Deconvolution Analysis of Differential Scanning Calorimetry Profiles. Kobunshi Ronbunshu 76 (2019) 150-156.

[16] J. Šesták. Thermophysical Properties of Solids, Their Measurements and Theoretical Analysis. Elsevier: Amsterdam, 1984.

[17] J. Šesták. Science of Heat and Thermophysical Studies: A Generalized Approach to Thermal Analysis, Elsevier, Amsterdam, 2005.

[18] H.L. Friedman. Kinetics of thermal degradation of char-forming plastics from thermogravimetry. Application to a phenolic plastic, J. Polym. Sci., Part C 6 (1964) $183-195$

[19] J.H. Flynn, L.A. Wall. General treatment of the thermogravimetry of polymers, J. Res. Nat. Bur. Standards, Part A 70 (1966) 4

[20] T. Akahira, T. Sunose. Method of determining activation deterioration constant of electrical insulating materials, Res. Report Chiba Inst. Technol. (Sci. Technol.) 16 (1971) 22-31

[21] M.J. Starink. The determination of activation energy from linear heating rate experiments: a comparison of the accuracy of isoconversion methods, Thermochim. Acta 404 (2003) 163-176

[22] S. Vyazovkin, D. Dollimore. Linear and nonlinear procedures in isoconversional computations of the activation energy of thermally induced reactions in solids. J. Chem. Inf. Comp. Sci. 36 (1996) 42-45.

[23] S. Vyazovkin. Modification of the integral isoconversional method to account for variation in the activation energy. J. Comput. Chem. 22 (2001) 178-183

[24] W.A. Johnson, K.F. Mehl. Reaction kinetics in processes of nucleation and growth. Trans. Am. Inst. Min. (Metall) Eng. 135 (1939) 416-42.

[25] M. Avrami. Kinetics of phase change I-general theory. J. Chem. Phys. 7 (1939) 110312.

[26] M. Avrami. Kinetics of phase change. II-transformation-time relations for random distribution of nuclei. J. Chem. Phys. 7 (1940) 212-24.

[27] M. Avrami. Granulation, phase change, and microstructure - kinetics of phase change III. J. Chem. Phys. 7 (1941) 177-84.

[28] Fraser RDB, Suzuki E. Resolution of overlapping absorption bands by least squares procedures. Anal Chem. 1966;38:1770-3.

[29] Perejón A, Sánchéz-Jiménez PE, Criado JM, Pérez-Maqueda LA. Kinetic analysis of complex solid-state reactions - a new deconvolution procedure. J Phys Chem B 2011;115:1780-91.

[30] Svoboda R, Málek J. Applicability of Fraser-Suzuki function in kinetic analysis of complex processes. J Therm Anal Calorim. 2013;111:1045-1056. 
[31] S. Vyazovkin, A.K. Burnham, J.M. Criado, L.A. Pérez-Maqueda, C. Popescu, N. Sbirrazzuoli. ICATC Kinetics Committee recommendations for performing kinetic computations on thermal analysis data. Thermochim. Acta 520 (2011) 1-19.

[32] R. Svoboda, J. Málek. Is the original Kissinger equation obsolete today? J. Therm. Anal. Calorim. 115 (2014) 1961-1967

[33] H.E. Kissinger. Reaction kinetics in differential thermal analysis, Anal. Chem. 29 (1957) 1702-1706

[34] R. Svoboda. Linear baseline interpolation for single-process DSC data - yes or no? Thermochimica Acta 655 (2017) 242 - 250.

[35] R. Svoboda. Tangential area-proportional baseline interpolation for complex-process DSC data - yes or no? Thermochim. Acta 658 (2017) 55-62.

[36] R. Svoboda. Importance of proper baseline identification for the subsequent kinetic analysis of derivative kinetic data, part 2. J. Therm. Anal. Calorim. 131 (2018) 18891897.

[37] R. Svoboda, J. Málek. Crystallization kinetics of a-Se, part 2: Deconvolution of a complex process - the final answer. J. Therm. Anal. Cal. 115 (2014) 81-91.

[38] R. Svoboda, J. Málek. Thermal behavior in Se-Te chalcogenide system: Interplay of thermodynamics and kinetics. J. Chem. Phys. 141 (2014) 224507.

[39] R. Svoboda, J. Málek. Thermal behavior of Se-rich $\mathrm{Ge}_{2} \mathrm{Sb}_{2} \mathrm{Se}_{(5-\mathrm{y})} \mathrm{Te}_{\mathrm{y}}$ chalcogenide system. J. Alloys Compd. 627 (2015) 287-298.

[40] R. Svoboda, D. Brandová, M. Chromčíková, M. Setnička, J. Chovanec, A. Černá, M. Liška, J. Málek. Se-doped $\mathrm{GeTe}_{4}$ glasses for far-infrared optical fibers. J. Alloys Compd. 695 (2017) 2434 - 2443.

[41] R. Svoboda, R. Bulánek, D. Galusek, R. Hadidimasouleh, Y. Ganjkhanlou. Crystal formation in vanadium-doped zirconia ceramics. CrystEngComm 20 (2018) 31053116.

[42] R. Svoboda, D. Brandová. Crystallization behavior of $\left(\mathrm{GeTe}_{4}\right)_{\mathrm{x}}\left(\mathrm{GaTe}_{3}\right)_{100-\mathrm{x}}$ glasses for far-infrared optics applications. J. Alloys. Compd. 770 (2019) 564-571.

[43] D. Brandová, R. Svoboda, Z. Olmrová Zmrhalová, J. Chovanec, R. Bulánek. Crystallization kinetics of glassy materials: the ultimate complexity? J. Therm. Anal. Calorim. 134 (2018) 825-834.

[44] N.V. Muravyev, A.N. Pivkina, N. Koga. Critical appraisal of kinetic calculation methods applied to overlapping multistep reactions. Molecules 24 (2019) 2298.

[45] G. Luciano, R. Svoboda. Activation energy determination in case of independent complex kinetic processes. Processes 7 (2019) - in press. 


\section{Table 1}

Kinetic parameters used to simulate the AC datasets and the corresponding Fraser-Suzuki [2830] asymmetry parameter $\mathrm{a}_{3}$.

\begin{tabular}{|l|l|l|l|l|l|l|l|l|l|l|}
\hline $\mathrm{E}_{1}$ & $\mathrm{~A}_{1}$ & $\mathrm{M}_{1}$ & $\mathrm{~N}_{1}$ & $\mathbf{I}_{\mathbf{1}}$ & $\mathrm{E}_{2}$ & $\mathrm{~A}_{2}$ & $\mathrm{M}_{2}$ & $\mathrm{~N}_{2}$ & $\mathbf{I}_{2}$ & $\mathrm{a}_{3}$ \\
\hline $\mathrm{kJ} \cdot \mathrm{mol}^{-1}$ & $\mathrm{~s}^{-1}$ & - & - & - & $\mathrm{kJ} \cdot \mathrm{mol}^{-1}$ & $\mathrm{~s}^{-1}$ & - & - & - & - \\
\hline 50 & $10^{2.7}$ & 0.44 & 0.88 & $\mathbf{0 . 3}$ & 300 & $10^{27}$ & 0.44 & 0.88 & $\mathbf{0 . 7}$ & -0.35 \\
\hline 50 & $10^{2.7}$ & 0.44 & 0.88 & $\mathbf{0 . 7}$ & 300 & $10^{27}$ & 0.44 & 0.88 & $\mathbf{0 . 3}$ & -0.35 \\
\hline 50 & $10^{2.7}$ & 0.54 & 1.08 & $\mathbf{0 . 3}$ & 300 & $10^{27}$ & 0.54 & 1.08 & $\mathbf{0 . 7}$ & -0.18 \\
\hline 50 & $10^{2.7}$ & 0.54 & 1.08 & $\mathbf{0 . 7}$ & 300 & $10^{27}$ & 0.54 & 1.08 & $\mathbf{0 . 3}$ & -0.18 \\
\hline 50 & $10^{2.7}$ & 0.66 & 1.32 & $\mathbf{0 . 3}$ & 300 & $10^{27}$ & 0.66 & 1.32 & $\mathbf{0 . 7}$ & 0 \\
\hline 50 & $10^{2.7}$ & 0.66 & 1.32 & $\mathbf{0 . 7}$ & 300 & $10^{27}$ & 0.66 & 1.32 & $\mathbf{0 . 3}$ & 0 \\
\hline 50 & $10^{2.9}$ & 0.81 & 1.62 & $\mathbf{0 . 3}$ & 300 & $10^{27}$ & 0.81 & 1.62 & $\mathbf{0 . 7}$ & 0.18 \\
\hline 50 & $10^{2.9}$ & 0.81 & 1.62 & 0.7 & 300 & $10^{27}$ & 0.81 & 1.62 & 0.3 & 0.18 \\
\hline 80 & $10^{6.3}$ & 1.00 & 2.00 & 0.3 & 300 & $10^{27}$ & 1.00 & 2.00 & 0.7 & 0.35 \\
\hline 80 & $10^{6.3}$ & 1.00 & 2.00 & 0.7 & 300 & $10^{27}$ & 1.00 & 2.00 & 0.3 & 0.35 \\
\hline
\end{tabular}

\section{Table 2}

Kinetic data-curves included in the particular evaluated datasets.

\begin{tabular}{|l|}
\hline included heating rates $\mathrm{q}^{+}\left(\mathrm{in}^{\circ} \mathrm{C} \cdot \mathrm{min}^{-1}\right)$ \\
\hline $0.5,1,2,3$ \\
\hline $3,4,5,6$ \\
\hline $8,11,13,16$ \\
\hline $25,50,75,100$ \\
\hline $150,200,300,400$ \\
\hline $0.5,1,2,3,4,5,6,8,11,13,16,25,50,75,100,150,200,300,400$ \\
\hline $3,4,5,6,8,11$ \\
\hline $13,16,25,50,75,100$ \\
\hline
\end{tabular}

\section{Figure captions}

Fig. 1: Left column: JMA complex data-curves simulated for kinetic parameters listed in the text. Range of included $\mathrm{q}^{+}$(see Table 2 for complete lists) and $\mathrm{I}_{1} / \mathrm{I}_{2}$ terms are denoted in each respective graph.

Right column: Corresponding (to the left-hand side graphs) E- $\alpha$ dependences provided by the differential and integral isoconversional methods. Vertical dashed line indicates $\mathrm{I}_{1} / \mathrm{I}_{2} ;$ horizontal dashed lines indicate $\mathrm{E}_{1}$ and $\mathrm{E}_{2}$. Included $\mathrm{q}^{+}$ranges are $0.5-3{ }^{\circ} \mathrm{C} \cdot \mathrm{min}^{-1}$ and $150-400{ }^{\circ} \mathrm{C} \cdot \mathrm{min}^{-1}$.

Fig. 2: Left column: JMA complex data-curves simulated for kinetic parameters listed in the text. Range of included $\mathrm{q}^{+}$(see Table 2 for complete lists) and $\mathrm{I}_{1} / \mathrm{I}_{2}$ terms are denoted in each respective graph. 
Right column: Corresponding (to the left-hand side graphs) E- $\alpha$ dependences provided by the differential and integral isoconversional methods. Vertical dashed line indicates $\mathrm{I}_{1} / \mathrm{I}_{2}$; horizontal dashed lines indicate $\mathrm{E}_{1}$ and $\mathrm{E}_{2}$. Included $\mathrm{q}^{+}$ranges are $3-6{ }^{\circ} \mathrm{C} \cdot \mathrm{min}^{-1}$ and $3-11^{\circ} \mathrm{C} \cdot \mathrm{min}^{-1}$.

Fig. 3: Left column: JMA complex data-curves simulated for kinetic parameters listed in the text. Range of included $\mathrm{q}^{+}$(see Table 2 for complete lists) and $\mathrm{I}_{1} / \mathrm{I}_{2}$ terms are denoted in each respective graph.

Right column: Corresponding (to the left-hand side graphs) E- $\alpha$ dependences provided by the differential and integral isoconversional methods. Vertical dashed line indicates $\mathrm{I}_{1} / \mathrm{I}_{2}$; horizontal dashed lines indicate $\mathrm{E}_{1}$ and $\mathrm{E}_{2}$.

Included $\mathrm{q}^{+}$ranges are $25-100^{\circ} \mathrm{C} \cdot \mathrm{min}^{-1}$ and $13-100{ }^{\circ} \mathrm{C} \cdot \mathrm{min}^{-1}$.

Fig. 4: Left column: JMA complex data-curves simulated for kinetic parameters listed in the text. Range of included $\mathrm{q}^{+}$(see Table 2 for complete lists) and $\mathrm{I}_{1} / \mathrm{I}_{2}$ terms are denoted in each respective graph.

Right column: Corresponding (to the left-hand side graphs) E- $\alpha$ dependences provided by the differential and integral isoconversional methods. Vertical dashed line indicates $\mathrm{I}_{1} / \mathrm{I}_{2}$; horizontal dashed lines indicate $\mathrm{E}_{1}$ and $\mathrm{E}_{2}$. Included $\mathrm{q}^{+}$ranges are $8-16{ }^{\circ} \mathrm{C} \cdot \mathrm{min}^{-1}$ and $25-400{ }^{\circ} \mathrm{C} \cdot \mathrm{min}^{-1}$.

Fig. 5: E- $\alpha$ dependences provided by the differential and integral isoconversional methods for the AC datasets simulated with $\mathrm{M}=1$ and $\mathrm{N}=2$. Range of included $\mathrm{q}^{+}$(see Table 2 for complete lists) is denoted in each respective graph. Vertical dashed line indicates $\mathrm{I}_{1} / \mathrm{I}_{2}$; horizontal dashed lines indicate $\mathrm{E}_{1}$ and $\mathrm{E}_{2}$. Included $\mathrm{q}^{+}$ranges are $0.5-3{ }^{\circ} \mathrm{C} \cdot \mathrm{min}^{-}$ ${ }^{1}, 3-6{ }^{\circ} \mathrm{C} \cdot \mathrm{min}^{-1}, 8-16^{\circ} \mathrm{C} \cdot \mathrm{min}^{-1}$ and $25-10{ }^{\circ} \mathrm{C} \cdot \mathrm{min}^{-1}$.

Fig. 6: E- $\alpha$ dependences provided by the differential and integral isoconversional methods for the AC datasets simulated with $\mathrm{M}=1$ and $\mathrm{N}=2$. Range of included $\mathrm{q}^{+}$(see Table 2 for complete lists) is denoted in each respective graph. Vertical dashed line indicates $\mathrm{I}_{1} / \mathrm{I}_{2}$; horizontal dashed lines indicate $\mathrm{E}_{1}$ and $\mathrm{E}_{2}$. Included $\mathrm{q}^{+}$ranges are $150-$ $400{ }^{\circ} \mathrm{C} \cdot \mathrm{min}^{-1}, 0.5-400{ }^{\circ} \mathrm{C} \cdot \mathrm{min}^{-1}, 3-11^{\circ} \mathrm{C} \cdot \mathrm{min}^{-1}$ and $13-100{ }^{\circ} \mathrm{C} \cdot \mathrm{min}^{-1}$.

Fig. 7: Selected E- $\alpha$ dependences provided by the differential and integral isoconversional methods for the $\mathrm{AC}$ datasets simulated with $\mathrm{M}$ and $\mathrm{N}$ parameters indicated in the graphs (the combinations of $\mathrm{M}=0.44+\mathrm{N}=0.88 ; \mathrm{M}=0.54+\mathrm{N}=1.08 ; \mathrm{M}=0.66+$ $\mathrm{N}=1.32 ; \mathrm{M}=0.81+\mathrm{N}=1.62$ ). Range of included $\mathrm{q}^{+}$(see Table 2 for complete lists) is denoted in each respective graph. Vertical dashed line indicates $\mathrm{I}_{1} / \mathrm{I}_{2}$; horizontal dashed lines indicate $\mathrm{E}_{1}$ and $\mathrm{E}_{2}$. Included $\mathrm{q}^{+}$ranges are $3-6^{\circ} \mathrm{C} \cdot \mathrm{min}^{-1}$ and $3-$ $11^{\circ} \mathrm{C} \cdot \mathrm{min}^{-1}$.

Fig. 8: Selected E- $\alpha$ dependences provided by the differential and integral isoconversional methods for the $\mathrm{AC}$ datasets simulated with $\mathrm{M}$ and $\mathrm{N}$ parameters indicated in the graphs (the combinations of $\mathrm{M}=0.44+\mathrm{N}=0.88 ; \mathrm{M}=0.54+\mathrm{N}=1.08 ; \mathrm{M}=0.66+$ $\mathrm{N}=1.32 ; \mathrm{M}=0.81+\mathrm{N}=1.62$ ). Range of included $\mathrm{q}^{+}$(see Table 2 for complete lists) is denoted in each respective graph. Vertical dashed line indicates $I_{1} / I_{2}$; horizontal dashed lines indicate $\mathrm{E}_{1}$ and $\mathrm{E}_{2}$. Included $\mathrm{q}^{+}$ranges are $13-100{ }^{\circ} \mathrm{C} \cdot \mathrm{min}^{-1}$ and $25-$ $100{ }^{\circ} \mathrm{C} \cdot \mathrm{min}^{-1}$. 

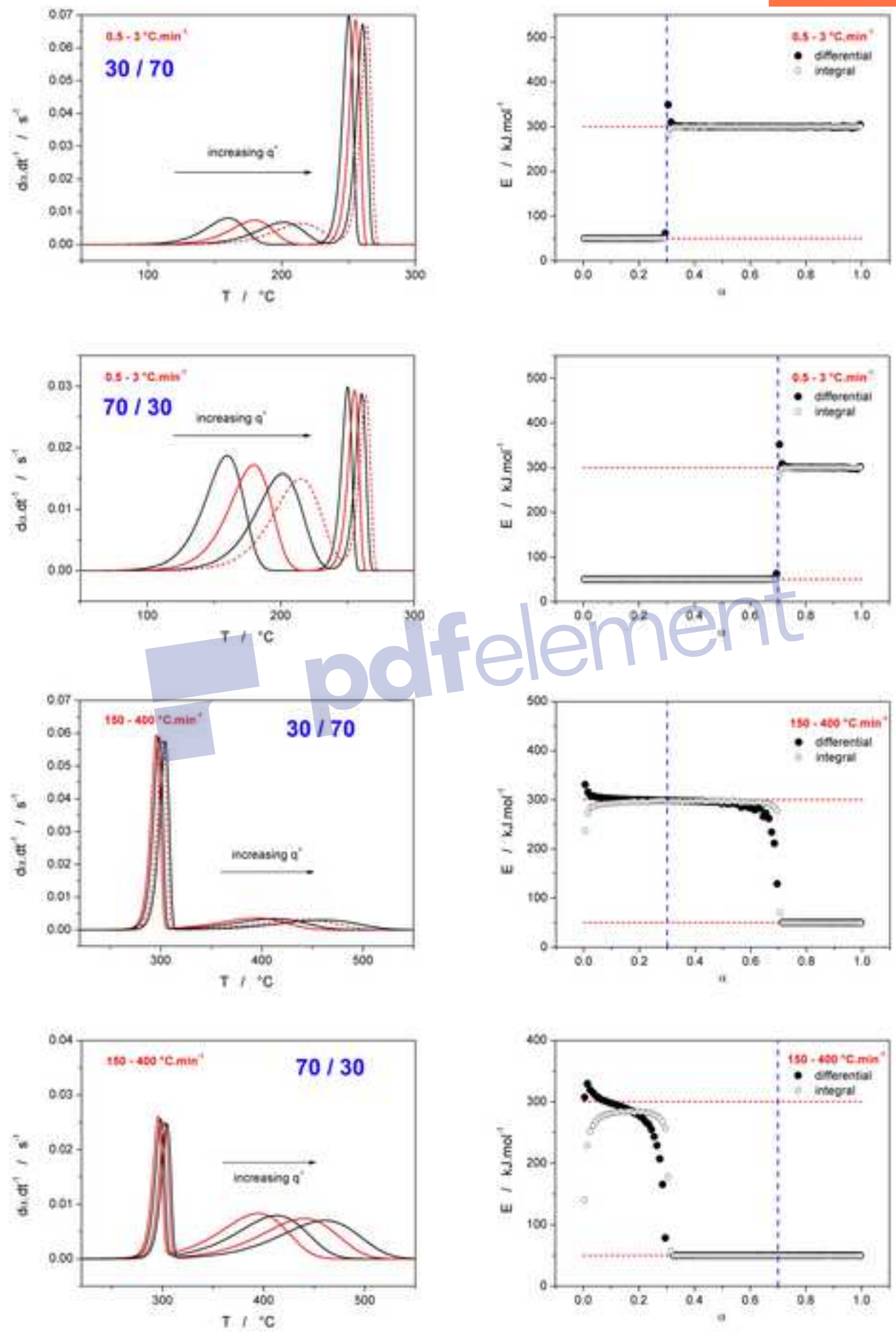

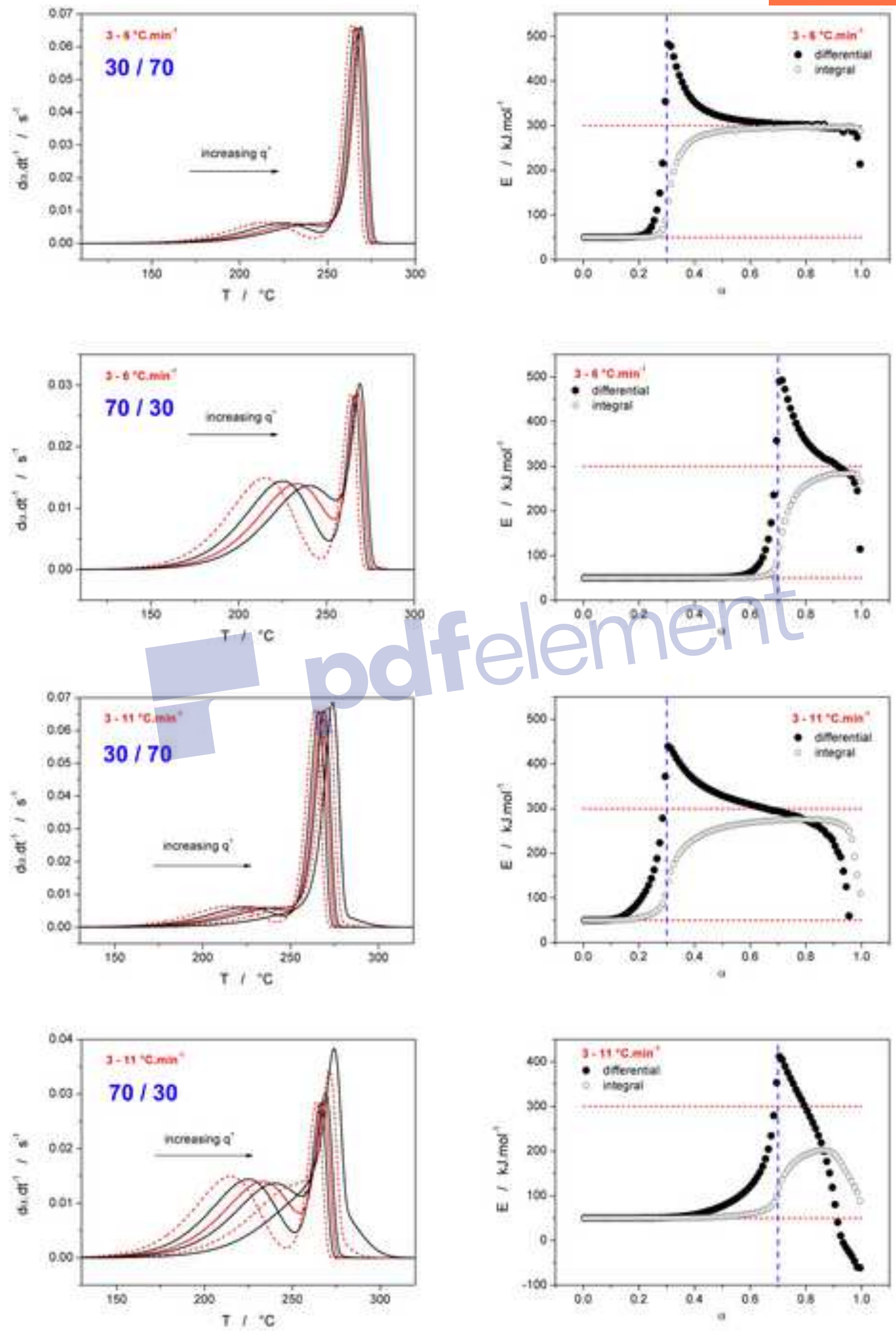

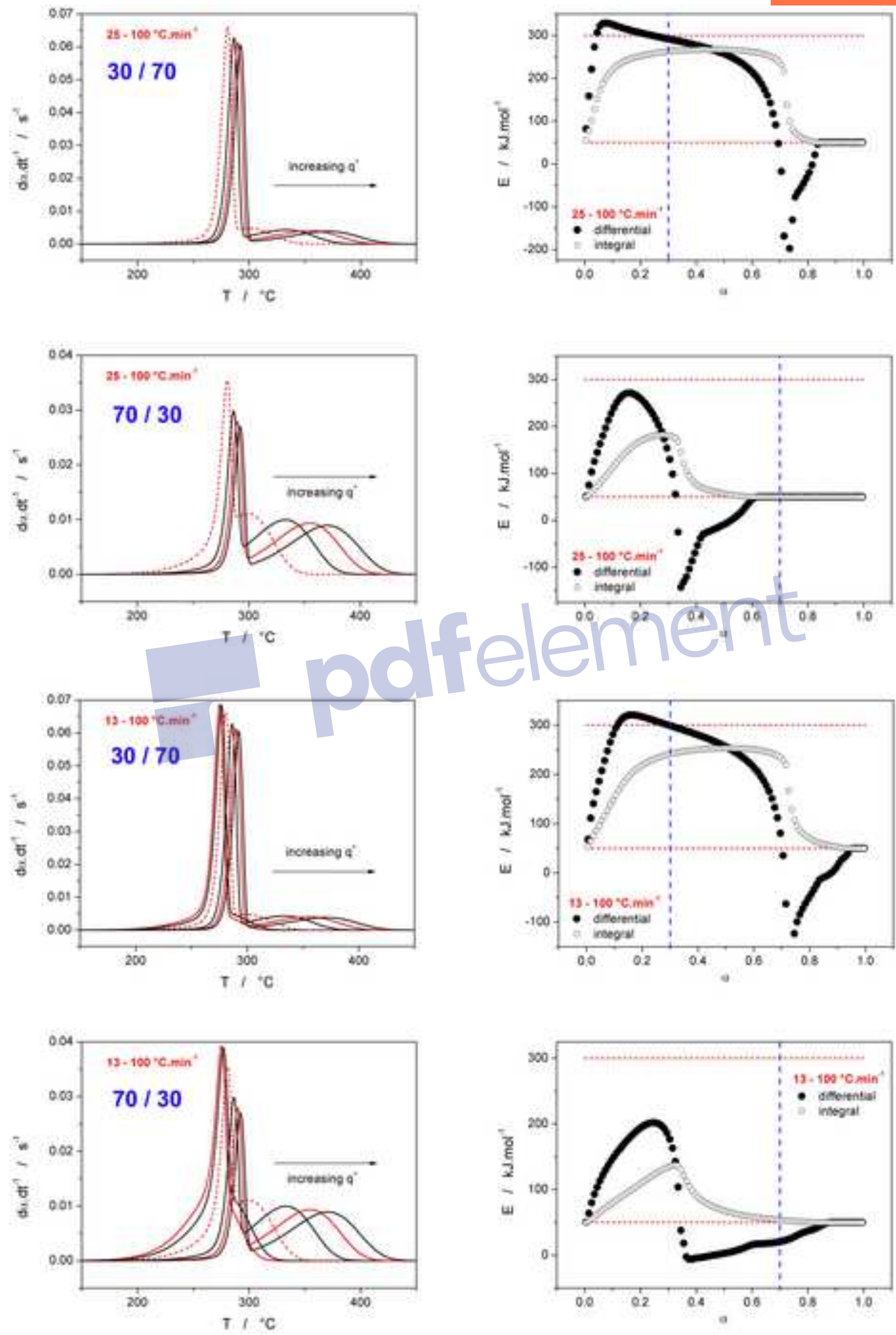
Figure 4
Click here to download high resolution image

Remove Watermark Now
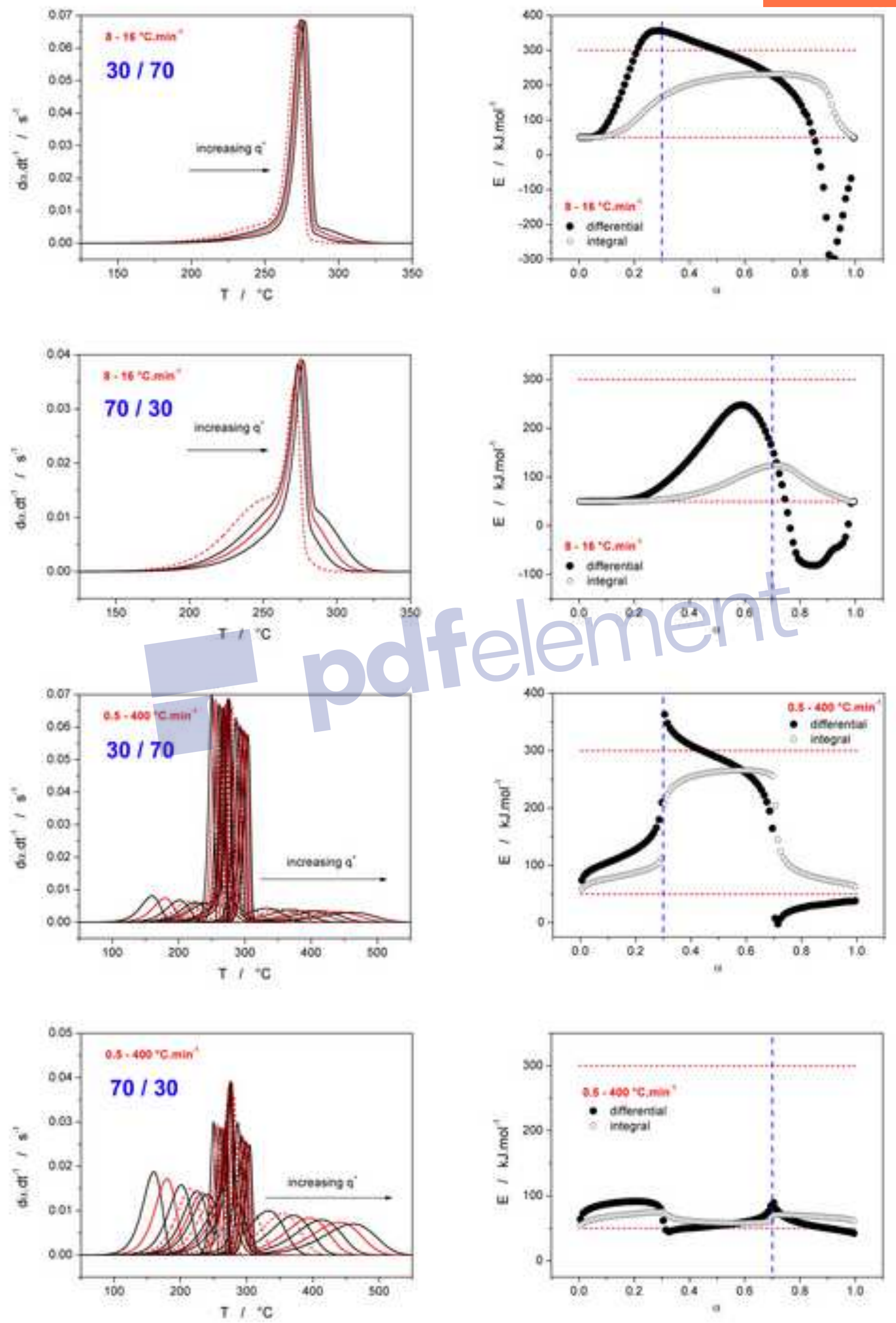
Click here to download high resolution image

Remove Watermark Now
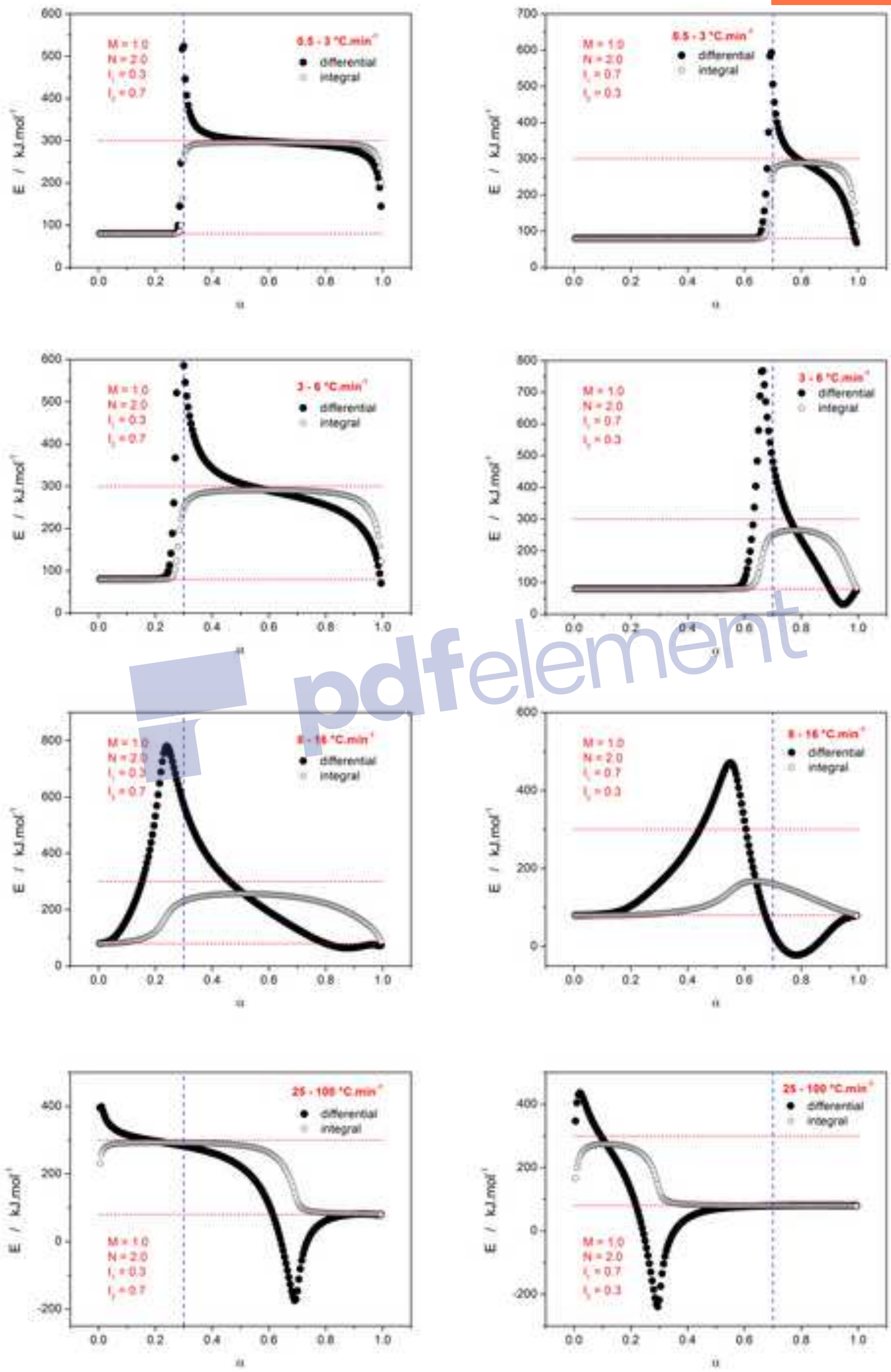
Click here to download high resolution image

Remove Watermark Now
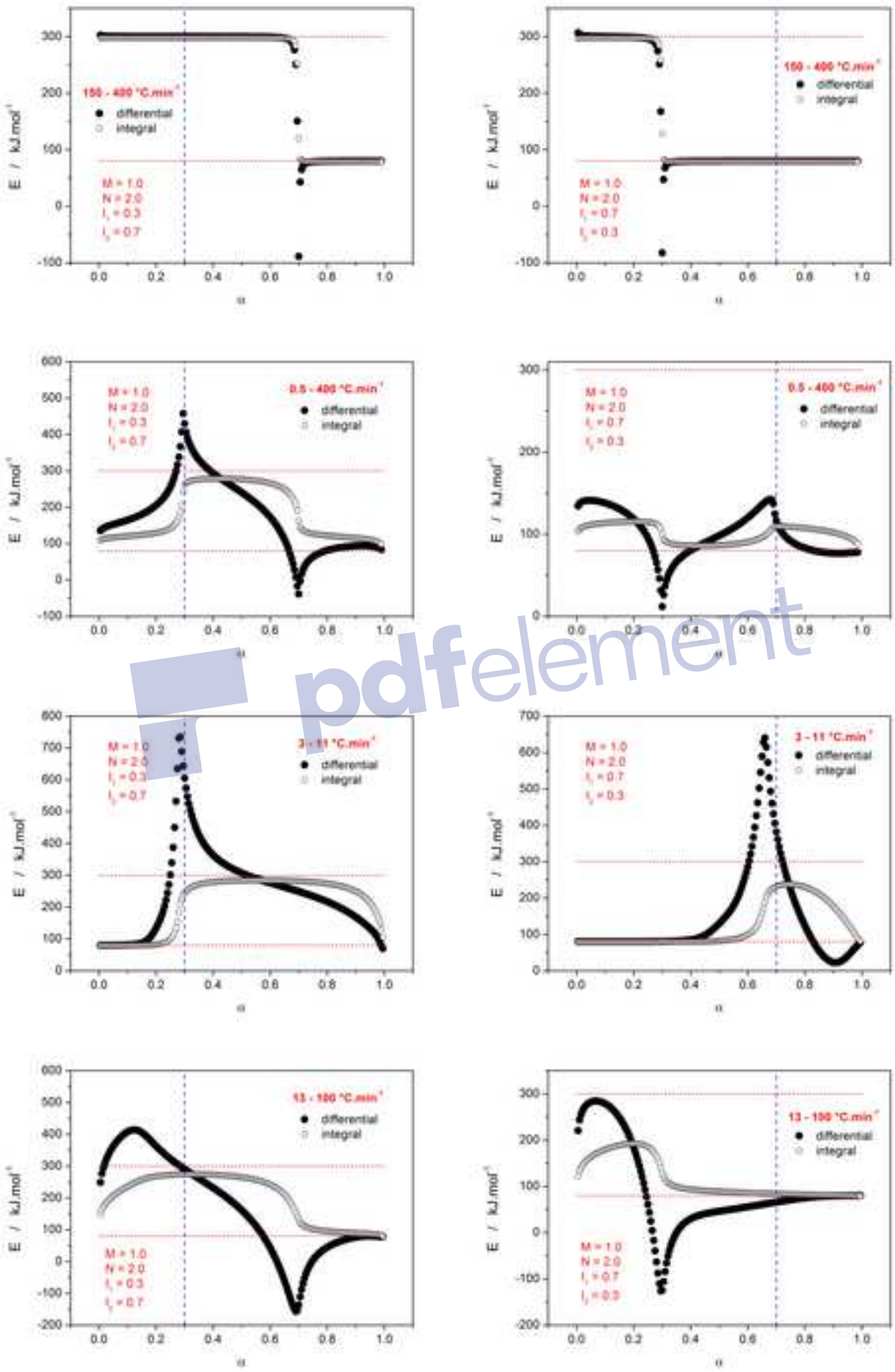
Figure 7
Click here to download high resolution image
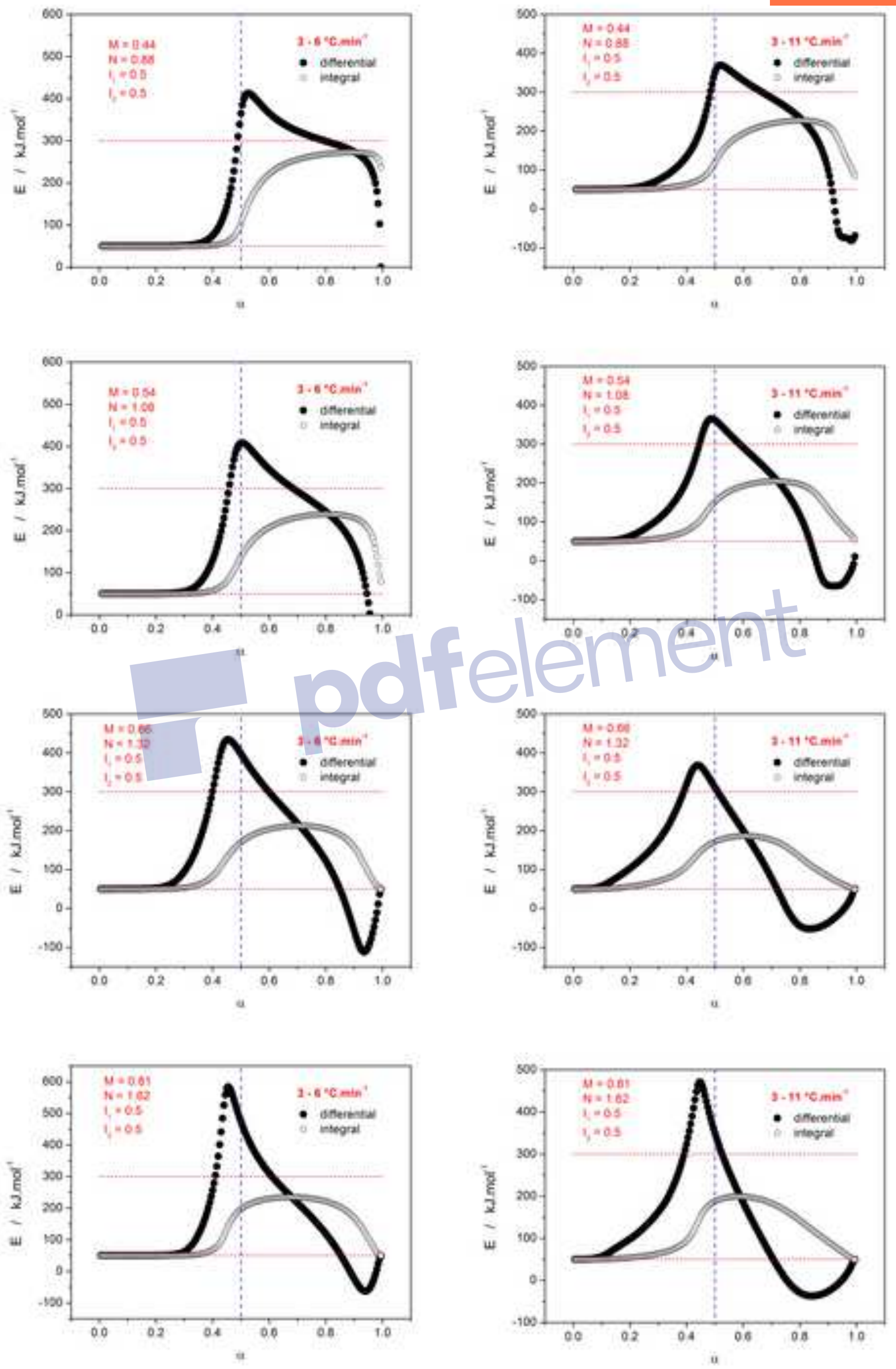
Figure 8
Click here to download high resolution image
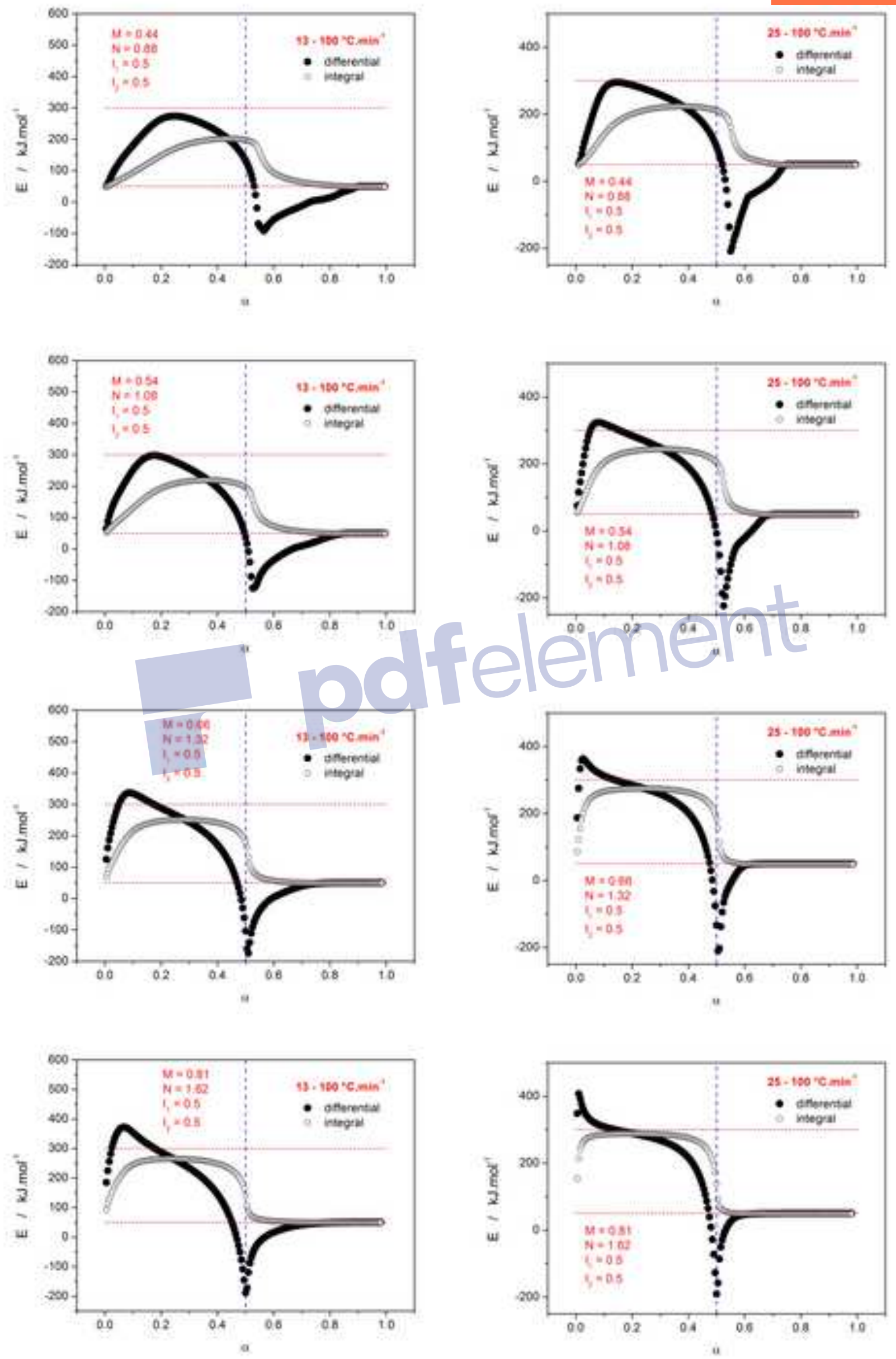